\title{
A Grammar of the Distinctive Competence Development at the Firm for the Solution of Systemic Problems
}

\author{
Bruno da R. Braga \\ bruno.rocha.braga@ifb.edu.br | Federal Institute of Education, Science and Technology of Brasília, \\ SGAN 610, 70830-450 Brasília, Brazil | Central Bank of Brazil, SBS Qd. 3 Bl. B, 70074-900 Brasília, \\ Brazil.
}

\begin{abstract}
Competitiveness results from factors beyond the structural conditions and organisational boundaries, such as inter-organisational cooperation. Using evidence gathered in Brazilian credit unions, this work reveals a type of social process for generating organisational capabilities and economic goods in firms satisfying needs defined by social structures in order to solve market failures and structural deficiencies in their socioeconomic systems. An exploratory and descriptive multiple case study with longitudinal qualitative data collected from a sequence of decision-making events of deterministic nature has made possible theoretical refinements to the model of competence development in the firm. It relies upon a systematic, computer-supported Process Tracing technique using a formal language model. Two case studies showed that firms hold relationships of cooperation and contribution with partners and nonmarket structures in their organisational and environmental surroundings whenever their performance is constrained by competitive problems of systemic nature, for which there is no solution based on the mechanisms of market price and state intervention.
\end{abstract}

Keywords. Core Competence; Systemic Competitiveness; Critical Realism; Category Theory; Generative Grammar Theory.

Cite paper as: Braga, B. da R., (2020). A Grammar of the Distinctive Competence Development at the Firm for the Solution of Systemic Problems, Journal of Innovation Management, www.open-jim.org, 8(2), 87-118.

Note: In 2015, the present work was published as a doctorate thesis at University of Brasília, Brazil. In 2017, the first draft of this paper was published in English at SSRN before being submitted to this Journal. 


\section{Introduction}

Competitiveness may be defined as the level of capabilities and performance of firms, industries, and political-administrative regions for the efficient exploitation of factors of production and the adequate supply of goods and services to the market in contrast with their competitors over time (OECD, 1994).

Trying to explain the phenomenon of competitiveness, several theoretical frameworks recognise both exogenous and endogenous factors such as structural and conjunctural conditions of the economy and non-inherited productive resources. In the long term, competitiveness does not rely on the business growth, the relativity of market prices, or the exploitation of comparative advantages, which are conditions the firm cannot manage, but on the development of productive resources as a source of sustainable competitive advantage. Thus, competitiveness does not relate to the ownership of raw resources acknowledged as valuable in the industrial economies. Instead, it relates to the takeover of resources, the ability to transform inputs into outputs to produce value for consumers, the speed of information processing, and the rate of innovation.

All models of competitiveness - as the Diamond model (Porter, 1990), the Structural model (OECD, 1992) and the Systemic model (Esser, Hillebrand, Messner, \& Meyer-Stamer, 1996) - assume this phenomenon is a result of the resource productivity and innovative capacity of firms. These competitive factors contribute to the expansion and diversification of the supply with reduction of market prices, fostering economic growth. However, these models diverge from each other regarding the type of process by which the phenomenon of competitiveness takes place.

For example, the Structural model of competitiveness assumes there are situations in which deficiencies in the productive system can disrupt some assumptions of market economies. In many late-industrialising countries, structural deficiencies accumulated over a historical process of development of the productive systems impose constraints on the performance of firms. If private action alone cannot solve them, then state intervention is necessary. In the past, experiments to address structural deficiencies through either state-owned investments in strategic industries or direct provision of public services occurred in countries of Latin America (Meyer-Stamer, 1998, 2005). Today, opportunities and capabilities for state intervention, even those not involving the direct allocation of public resources, such as market regulation, are increasingly limited. Furthermore, the involvement of big corporations in the efforts of technology transfer and production chain management may also be insufficient to make economic development inclusive. In these circumstances, state intervention is still necessary. In this regard, OECD (1992) argues for the selective support to firms promoting the shift from a restrictive comparative advantage-based condition to a competitive advantage-based one.

The sustainable economic performance of firms and their ecosystems of production is dependent upon actions coordinated with other actors (e.g., the government, industry supporting institutions, and the civil society). Networking is such a tool to promote the collective creation of resources and collaborative learning. In a multidimensional and systemic view of competitiveness, it becomes such a critical determinant not only of performance but of the sustainability of the firm. The firms and industry supporting institutions enrolled in collective actions coexist 
within the micro and mesoeconomic levels of the organisational surroundings of their ecosystems (Esser et al., 1996).

Government action is also not restricted to be an exogenous factor of competitiveness. Some market failures and structural weaknesses can accumulate during the historical development of the productive system. If they prevent the satisfaction of a number of assumptions of that models of competitiveness, then government action - not only in the form of sectoral public policies but also of cooperation with other firms and meso level institutions - is necessary. Esser et al. (1995) justify cooperation between actors of the public and private sectors when the government objectives cannot be achieved by direct action only, as they rely on some idiosyncratic resources of firms and industry supporting institutions, or when the implementation of public programs would be very costly or ineffective without these private-sector organisations.

The Systemic model acknowledges some problems constraining the competitiveness of firms like market failures and structural deficiencies in their productive systems. In this way, either the private sector's actions relying on the price mechanism or the public sector's actions relying on state intervention mechanisms (i.e., public policies and regulation) cannot solve these competitive problems. In these circumstances, no single actor owns all the resources required to craft the definitive solution in one shot; they are called systemic problems (Chaminade, Lundvall, Vang, \& Joseph, 2009). As a result, collective action in the search for solutions to systemic problems may arise as a kind of social process for the creation of specific assets and capabilities in firms.

Inter-organisational relationships between firms and industry supporting institutions encourage the development of capabilities in line with the trend of partial replacement of the direct state intervention by the collective action of local actors on endogenous determinants of innovation (Meyer-Stamer, 2005). The Systemic model recognises the development of capabilities in the firm to create economic goods to the market but not to meet needs from other social structures of the productive system in the search for solutions to systemic problems. The firm transforms social structures that regulate the market functioning by solving competitive problems limiting its performance in a way that improves the socioeconomic system around it as well.

This work delineates the distinction between the mechanism of cooperation between the firms and industry supporting institutions in their organisational surroundings for creating idiosyncratic resources and the mechanism of contribution from the firm to a nonmarket structure in its environmental surroundings to solve the systemic problem. Both comprise separate theoretical relations in the Systemic Competitiveness model. The firm's contribution to systemic competitiveness, neglected in the original model, is a theoretical contribution of this work. It aims to explain this social phenomenon by acknowledging the ontological and epistemological assumptions of the post-positivist paradigm known as Critical Realism (Bhaskar, 1975). In contrast to the mainstream paradigm, Social Positivism, there is a shift from the naïve realist assumptions like the direct measurement of phenomena to an ontological stance relying on a stratified reality and unobservable mechanisms yielding empirical events. Another change is the epistemological approach for theory formulation relying on a logic of retroduction instead of a logic of falsification. Both paradigms endorse deduction of hypotheses for empirical validation and evidence accumulation, but the former rejects the principle of objective rationality and the rule-of-thumb test of hypothesis against sample data as the criteria to accept the "scientificity" of a theoretical 
statement. In contrast, social researchers modify the empirical model to conciliate divergences between theory and evidence due to contextual specificities.

This research is a multiple case study that applies a systematic, computer-supported process tracing procedure relying upon a discrete mathematical model (Braga, 2016, 2017, 2018). It has two components based on both combinational logic and sequential logic. The first describes every single decision-making or action event exerted by a single agent using a pair of qualitative methods. On the one hand, a deductive method applies a classification system for types of events using Qualitative Content Analysis (Krippendorff, 2013). On the other hand, an inductive method takes configurations of contextual conditions to hypothesise the best explanation for any surprising fact using Qualitative Comparative Analysis (Ragin, 1987). The second component describes a category of complex, dynamic and contingent social process using a rule-based model of patterns of relations between events in chronological order. A retroductive method suggests modifications to a formal model deduced from Generative Grammar Theory (Chomsky, 1956, 1959) much like Sequence Analysis (Abbott, 1990, 1995) on two or more instances of that social process taken together.

There are some studies relying on the concept of grammar in the social sciences, such as those focused on social practices (Bourdieu, 1977, 1980), organisational processes (Pentland, 1995), and institutions (Crawford \& Ostrom, 1995). Nevertheless, none of them uses such a formal, mathematical model to provide "systematicity" for the task of empirical data analysis. The foundations of the sociology of complexity need both a stratified ontology based on the generative model and a retroductive logic based on the critical realist assumptions.

Elinor Ostrom received the 2009 Nobel Prize in Economics because of her works on the governance of common-pool resources. She proposed a grammar-based analytical approach called Institutional Analysis and Development (IAD) framework. This paper introduces both theoretical and methodological advances in this line of research. First, systemic competitiveness turns into a common good of firms and other organisations embedded in the same socioeconomic system. Thus, firms need making investments to preserve systemic competitiveness in the long term, which are their contributions in terms of quasi-public economic goods. Second, the Process Tracing technique, which accepts the assumptions of Critical Realism, acknowledges generative mechanisms. Indeed, the coupling of collective actions in which the firm takes part with partners in its organisational surroundings in favour of systemic competitiveness is a mechanism. Third, the Process Tracing technique also rejects the assumption of methodological individualism of Karl Popper's Situational Analysis in which Ostrom's research rests on. Finally, the data analysis procedure relies upon a discrete mathematical model that goes further in comparison to the IAD framework regarding both explanatory power and inference reliability. It identifies patterns of sequences of shared strategies, norms and rules within social processes in a more realistic way.

The theoretical and methodological approaches designed in this work can contribute to the view of the Dynamic Capabilities of the firm (David J. Teece, Pisano, \& Shuen, 1997), which relies upon Evolutionary Economics (Nelson \& Winter, 1982). There is no axiomatic methodology aimed to investigate the socioeconomic phenomenon of the endless reconfiguration of resources over time to adapt the firm to its competitive environment. In fact, a realistic, systems-based 
theory of the firm (or an intelligence-based view of competitive advantage) is the main goal of this research program.

\section{The Research Problem and the Proposed Theoretical Model}

Neoclassical economics acknowledges that some system of incentives for competition is a necessary condition to make firms engage in learning processes. These incentives aim to raise the level of efficiency in resource allocation. Competition operates such as a mechanism for the structural adjustment of the market based on its prices. It implies the assumption of market self-regulation, which is the inexorable tendency for selective market pressure to eliminate inefficient firms. Their performance relies upon operational efficiency only, and then, performance heterogeneity between the firms is non-existent or transient in perfectly competitive markets. However, this assumption cannot explain differences that persist in some firms when compared to their rivals due to structural constraints causing a kind of imperfect competition (Robinson, 1933) or monopolistic competition (Chamberlin, 1933). In contrast, the higher economic performance of some firms may be explained by imperfections in the product market, which reduces the competition among them below the socially optimum level (Caves \& Porter, 1977; Porter, 1979). Alternatively, the firm's superior performance may be explained by imperfections in the factor markets, which include natural resources, investment capital, labour, business skills, and technology (Rumelt, 1984; Wernerfelt, 1984). Nevertheless, these structuralist worldviews do not acknowledge the agency of entrepreneurs for the construction and renewal of competitive advantages, which is a common phenomenon (Chandler, 1962, 1992). In works of Industrial Organization, the concept of core competence refers to the source of such advantages that occur in innovative firms operating in competitive markets (Prahalad \& Hamel, 1990).

\subsection{A Social Process for the Firm's Competence Development}

Borrás and Edquist (2013) say the concept of organisational competency belongs to the class of resource stock while competence development belongs to the class of resource flow. This means the creation and exploitation of a bundle of specific assets, information, knowledge, capabilities and competencies at firms to solve competitive problems through a trajectory of projects that is contingent on a specific configuration of contextual conditions (Nicolai Juul Foss, 1996). A kind of evolutionary process entails changes both inside and outside the firm to satisfy needs defined in a social structure in its environmental surroundings. While this process incessantly approaches a definitive solution to the competitive problem, it reveals competence development relying on the competencies of the firm (Bourgeois III, 1984; Javidan, 1998).

The retention of competencies in the firm is a kind of organisational learning process, a result of complex interactions between contextual conditions and the resource stock built up over time (Borgatti \& Foster, 2003; Goerzen, 2007). These social interactions are the instances of types of events in the process of competence development. The development of capabilities and economic goods over time leads to the adaptation of firms to market demands in the form of at least one core competence (Nicolai Juul Foss, 1996). This phenomenon takes place through the activation 
of some underlying generative mechanisms; however, it is also constrained by the context of the firm: the conditions present in its environmental and organisational surroundings that influence its performance (Lawson, 2004).

The external environment is a sort of competitive, economic, institutional, political, technological and social conditions surrounding an organization (Esser et al., 1996; Porter, 1990). Consider that the external environment of the firm is a system of social structures influencing both its behaviour and performance. Each social structure is a recurrent pattern of interactions between social actors maintained through incentives and sanctions; it either creates or constrains opportunities and threats to the firm over time (Barker, 2005; Coleman, 1986).

From the point of view of the firm, the market is the most important social structure: it is the source of financial resources, which are those indispensable for acquiring all other resources (Coase, 1937). Nevertheless, it is not the only one. There are social structures such as dimensions of the environmental surroundings of the firm that still conditionate its behaviour. For example, credit unions are under the influence of both the regulatory environment and the community environment.

Bourgeois (1984) maintains that firms do not respond passively to the conditioning exerted by the environmental surroundings because they actively adjust their resource settings to satisfy the environmental demands and implement their business strategies. This process of change relies upon the organisational competencies of the firm, a type of knowledge-based resource. The firm may also establish types of relationships with other firms and industry supporting institutions in their organisational surroundings to acquire idiosyncratic productive resources, but it also develops competence internally by combining shared resources with their own stock of resources. Nevertheless, the present work proposes this kind of social process may not result in a marketoriented core competence, but in a kind of competence oriented to other social structure in the environmental surroundings of the firm that supplements the market functioning.

\subsection{A Social Process for the Firm's Inter-organisational Relationships}

Between the structure of the industry and the boundaries of the firm, there is a place for developing some productive factors: the organisational surroundings, which share resources that are complementary to those of the own stock of the firm. The internal environment of the firm and its relationships with other firms and industry supporting institutions embrace a social structure in the form of network enabling entrepreneurial agency.

Inter-organisational relationships enable competence development through two social processes for the creation of specific assets and capabilities at the firm (Dyer \& Singh, 1998). First, the firm's process of combining idiosyncratic, non-transferable shared resources that are complementary to its own stock of resources (Doz, 1996). Second, the firm's process of information and knowledge exchange with partners that are not available to its rivals, which promotes learning and innovation (Grant, 1996). In this way, the differences between firms in their ability to exploit resources explain part of the performance heterogeneity observed in similar organisations of the same sector as well (DeCarolis \& Deeds, 1999).

Firms embedded in the same inter-organisational network can collectively develop a shared com- 
petence. However, Camisón (2004) observed heterogeneity between firms of the same sector, suggesting it occurs because of resources that are not available to other firms; probably due to specific relationships in the organisational surroundings and the idiosyncrasy of their stock of inherited and endogenously developed resources (Camisón, 2004; Teece, 1986). Finally, social interactions between the distinctive competence and the shared competence may generate economic value to consumers and new sources of rent to the firm. This complex of social interactions is a factor of competitive advantage.

These theoretical perspectives on competence development (Lawson, 1999) and inter-organisational relationships (Dyer \& Singh, 1998) can consider social structures in the environmental and organisational surroundings when explaining the competitiveness of firms embedded in a socioeconomic system. As any rational agent, the firm makes the internal adjustment of its resource configuration to the contextual conditions of its surroundings by means of developing capabilities and economic goods to solve some competitive problems. In addition, the firm's actions supported by its partners in the organisational surroundings make changes in the social structures of its environmental surroundings (Walker Jr. \& Ruekert, 1987). Any explanation for the social process of competence development in the firm needs capturing the dynamics of its own actions from a historical or processual viewpoint.

\subsection{The Hypothesis of the Distinctive Systemic Competence Development in the Firm}

The premise of the multidimensional and systemic competitive performance of the firm considers both the market failures and structural weaknesses of the productive systems that inhibit the operation of the mechanism for the structural adjustment of the market based on prices (MeyerStamer, 2005). This view assumes that the market is the locus of the competitive process, but it still acknowledges other social processes contributing to systemic competitiveness as well.

Consumers cannot directly perceive all dimensions of the firm's competitiveness in the attributes of the goods and services offered to them (Hertog, 1999). For example, there are both positive and negative externalities of the private business that markets cannot price, information asymmetries that undermines the rationality of economic agents in consumer relationships, and innovations changing preferences of consumers and creating a wholly new market. These are competitive dimensions of the firm that the market cannot price, but both the coordination and institutionalisation processes in social networks involving the regulator and other industry supporting institutions can shape these dimensions of the competitive behaviour of the firm (Finger \& Varone, 2006b, 2006a).

Some productive sectors do not have enough selective pressure to eliminate all firms that do not match the efficiency standard (e.g., regulated industries, oligopolies); there is also no guarantee the observed standard is the highest possible level of excellence (Nelson \& Winter, 1982). In these industries, competitiveness depends not only upon the structural conditions but also upon sectoral policies and government regulations. Limited government action and increasing competitive pressure can likely promote the search for new models of economic governance using inter-organisational processes to foster a structural change; these include the coordination of ac- 
tors at the local, regional, national and multilateral levels. The socio-technical interactions and the competitive resources distributed between actors at the micro and meso levels of the socioeconomic system exert a growing influence on the efficiency, innovation and strategic coherence of the actions of the firms (Esser et al., 1996).

The market cannot price many productive resources, which need the active role of the government in their creation and exploitation. Thus, the solution to systemic problems still relies upon non-interventionist government actions taken together with other firms and industry supporting institutions. This work proposes the contribution of firms to the competitiveness of their socioeconomic systems may occur through the development of a kind of competence that does not create products to the market; it rather creates organisational capabilities and quasi-public goods to satisfy needs defined in other social structures, in the search for solutions to systemic problems.

In this perspective, the environmental surroundings can shape the behaviour of the firm by establishing needs whose satisfaction may overcome some systemic problems constraining its performance. The organisational surroundings may offer idiosyncratic resources to enable the agency of the firm on social structures of its environmental surroundings. Competitiveness follows the efficient use of idiosyncratic resources for market competition. Nevertheless, it also requires the effective exploitation of these productive resources to satisfy criteria established by other social structures, creating contextual conditions for the sustainability of a socioeconomic system.

The firm has to be the protagonist of some collective actions with the support of other actors in its socioeconomic system to solve the systemic problems. The entrepreneur fosters some relationships with partners in the organisational surroundings creating capabilities and economic goods to meet both market and systemic needs. The firm is in the interface between the market and its socioeconomic system such as a privileged actor integrating information and knowledge from other social structures comprising its organisational and environmental surroundings. This behaviour contributes to the search for solutions to systemic problems.

The present work extends the Systemic model (Esser et al., 1996) by distinguishing core competence and systemic competence. In both, description of the competence development process using evidence gathered from the empirical setting of the firm is still the same: a complex pattern of relations of interdependence and socio-technical interactions between a set of firms and industry supporting institutions delimiting a kind of socioeconomic system. Instead, the purpose of the firm engaged in such an evolutionary path that is different.

The development of competence is supposed to be separate and causative of the growth of the firm; nevertheless, it is at a level of reality that is inaccessible to the perception of the researcher, constrained to the empirical evidence of events occurred during the process. Competence may be a factor of competitiveness, but it is still not directly observable in the empirical settings during research. Consequently, projects, capabilities, products, market position, and economic performance of the firm are still real-world manifestations of the events generated by hidden mechanisms underlying the competence development process at the firm (Lawson, 1999).

The firm developing competence for the sustainability of its socioeconomic system still seeks the maximisation of its economic performance; however, the firm satisfies criteria defined by 
institutions and coordination structures between diverse actors at the micro and mesoeconomic levels instead. In this analytical framework, the search for evidence of competence development relies upon an evolutionary path of chains of decision-making events taking place at the firm. The paradigmatic type of critical event is the generation of capabilities and economic goods by the firm to satisfy needs defined by systemic dimensions of its environmental surroundings. The sources of systemic competence development are micro and meso level institutions that share resources with firms comprising the socioeconomic system (Camisón, 2004). Both transferrable and non-transferrable idiosyncratic resources offered through relationships between firms and their partners in its organisational surroundings still occur in the process of systemic competence development.

The firm's projects are evidence of the social process for generating capabilities and economic goods to solve competitive problems, that is, the competence development process (Jessop, 2001). Projects are the units of analysis in this research approach. For systemic problems, the firm's projects encompass some partners in its organisational surroundings. In this case, collective actions must instead be units of analysis because they contain the empirical evidence supporting a set of theoretical propositions about the systemic competence development process.

The firm continuously fosters changes in its configuration of resources in the search for solutions to systemic problems relying on shared competence. This development occurs with the support of meso level institutions providing idiosyncratic resources to firms in the same socioeconomic systems. Both the micro and mesoeconomic levels exert pressure on the structural homogeneity of any shared competence (Camisón, 2004). Systemic competence is a kind of shared competence among firms embedded in the same socioeconomic system. It is still necessary to explain the behaviour of the firm investing in distinctive systemic competence development in light of the contextual conditions that make this a rational behaviour.

The assumption that the firm is a rational economic agent suggests there is no need for additional investments in the development of a distinctive competence when there are no conditions promoting the generation of new sources of economic rents and the creation of competitive advantages for the firm. Investing in the development of any distinctive systemic competence can be economically feasible due to at least three hypothesised contextual conditions. The first condition is the high economic impact of the systemic problem in the firm's performance by constraining both economic and social outcomes (Esser et al., 1996). Another condition is the high rivalry in both the current and potential markets limiting opportunities relying exclusively upon the core competence of the firm (Makadok, 2001, 2006). The last contextual condition is the appropriation of a part of the benefits generated by the firm for the socioeconomic system in which it operates in the form of new sources of rent (Peteraf, 1993). The theory suggests beginning with the search for flows of knowledge and information to the firm, which precedes other event of combination of non-transferable, idiosyncratic resources from its partners, and then, identifying the generation of an economic good of systemic nature. All these social processes underlying the competence development at the firm and the contextual conditions present in its environmental and organisational surroundings may enable the contribution of the firm to systemic competitiveness. 


\section{The Goal and Reasons for a Multiple Case Study}

This paper proposes answering the research question using the domain of Brazilian credit unions, which is organised in a kind of hierarchical network with three levels: the unions, central cooperatives, and confederations. Inter-organisational relationships between credit unions and other industry supporting institutions, including the state regulator, which is the Central Bank of Brazil, delimit their socioeconomic system.

Since the unions' competitiveness is multidimensional and systemic (Chandrasekhar, 2007; Kawai, Mayes, \& Morgans, 2012), the selection of cases to investigate must maximise the chance of finding the hypothesised pattern of empirical evidence out of a sequence of events related to capabilities and economic goods generated by the firm to satisfy the needs defined by a social structure in its environmental surroundings. In other words, this firm must demonstrate a high level of contribution to at least one of the systemic environmental dimensions that are relevant to its own performance. In this situation, this case is distinctive regarding the average rational behaviour.

Credit unions operate as small-scale banking institutions in market niches, but they do not seek profits. A remarkable feature of this sector of the Brazilian banking industry is the networking organization of credit unions around central cooperatives ${ }^{1}$. Different from banks, whose operations are capital-intensive, credit unions are relationship-intensive regarding their members and industry supporting institutions. In this sector, competitive advantage relies upon banking product customization to the needs of the local market. The credit unions deliver suitable services in a distinctive pattern when compared to banks. Both the standard products supplied by the cooperative bank and the resources shared by partners in the organisational surroundings become merged in the search for customization (e.g., financing lines for the acquisition of technologies, readily available service stations, and unconventional credit guarantees). Of course, there are competitive problems that their core competence can still solve, such as the information asymmetries between the credit unions and their consumers that constrain the perceived value of their products and services, and the prohibitive costs of some market transactions. However, there are also problems of systemic nature.

Some products based upon the relationship between the firm and its consumers target market failures and structural weaknesses in the socioeconomic system, but they are not systemic goods offered to an environmental dimension supplementing the market. Both resemble each other because of the mechanisms that generate them - finding out solutions to problems that constrain firm's performance. The products satisfy market needs, but not the systemic needs defined by other social structures. Some solutions rely upon competence that is not market-oriented but system-oriented.

This research considers that credit unions are firms operating in competitive markets such that they carry out rational actions to raise their sustainable economic growth. The generative mechanisms underlying the competence development process should be the same in the situation

$1 \quad$ In Brazil, there is a third-level institution called Confederation, which creates a kind of nationwide network, a credit cooperative system. There are four Confederations and their respective credit cooperative systems in this country. 
of systemic competence development. On the one hand, an ordinary core competence influences the attributes of products and services created to the market. On the other hand, the systemic competence influences the attributes of quasi-public economic goods created for the benefit of the socioeconomic system as a whole.

There are two social structures promoting the competitiveness of the sector of credit unions in Brazil: (1) the local community and (2) the regulatory environment. A pair of firms with evidence of excellence in systemic competence development for each of the above environmental dimensions are respectively: (1) Cooperativa de Crédito de São Roque de Minas (Saromcredi) and (2) Cooperativa de Crédito dos Funcionários de Instituições Financeiras Públicas Federais (Cooperforte).

\section{Operationalizing Process Tracing using a Grammar Model}

In a qualitative research strategy based on case studies, the Process Tracing technique systematically describes a chain of events recognized in the text narrative; however, it is such a strictly descriptive research approach. Moreover, it is viable to identify some recurrent patterns between events in the course of a social process in the ontological level (i.e., regularities that are independent of the domain of study) using an analytical approach.

The achievement of this need is possible using a data analysis procedure comprising three inferential approaches: a deductive method using Qualitative Content Analysis (Krippendorff, 2013); an inductive method using Qualitative Comparative Analysis (Ragin, 1987) implementing the Quine-McCluskey algorithm for simplifying binary functions based on combinatory logic (Quine, 1952); and a retroductive method using Sequence Analysis (Abbott, 1990, 1995). Moreover, the retroductive method (Braga, 2017, 2018) relies upon a discrete mathematical model of the mechanisms involved in the generation of sequences of events which is deduced from Generative Grammar Theory (Chomsky, 1956, 1959). The mathematical grounds of this kind of modelling technique includes: Category Theory (Eilenberg \& MacLane, 1945; MacLane, 1948); Disjunctive Prime Form of logical functions (Blake, 1937; Quine, 1952); and Formal Language Theory (Post, 1936; Turing, 1939), which is an extension of Set Theory that acknowledges the complex mappings that are in use in Generative Linguistics.

In the next sections, the specification of these three analytical methods relying upon that discrete mathematical model provides reliability to this multiple case study.

\subsection{Deductive Qualitative Content Analysis for the Classification of Events}

This section introduces the terminal symbols that are in use for the task of classifying the instances of types of action events. The categorical structure (S), the Competence Development (CD) process, consists of the underlying sub-processes of Generation of Capabilities and Economic Goods (GG) and Relationships with Partners (RR). The first process (GG) consists of an outcome of the type of event for the generation of an economic good $(\mathrm{G})$ preceded by an instance of the inter-organisational relationships sub-process $(\mathrm{RR})$. The latter is any sequence of partnerships 
occurring in projects of the firm $(\mathrm{R})$ : either for the combination of idiosyncratic, non-transferable resources $(\{\mathrm{c}\})$ or information and knowledge exchange $(\{\mathrm{i}\})$, which are alternative outcomes for events of inter-organisational relationships.

The theoretical concepts used in this paper constitute a hierarchical structure, which should be represented as shared prefix referring to the existing super-classes such that each pair of these concepts is set apart by the character ' $Y$ ' (Table 1).

Table 1. The relationship between mechanisms, attributes, and contextual conditions.

\begin{tabular}{ll}
\hline Types of Events & Attributes and Contextual Conditions \\
\hline Generation of Capabilities and & \#Attribute $\backslash$ NeedToSatisfy $\left(\left\{\mathrm{a}_{1}\right\}\right)$ \\
Economic Goods: & \#Attribute $\backslash$ DistinctiveContribution $\left(\left\{\mathrm{a}_{2}\right\}\right)$ \\
\#Event $\backslash$ GenerationOfEconomicGood & \#Context $\backslash$ External $\backslash$ Problem $\left(\left\{\mathrm{k}_{1}\right\}\right)$ \\
$(\mathbf{G} \rightarrow\{\mathbf{g}\})$ & \#Context $\backslash$ External $\backslash$ Appropriability $\left(\left\{\mathrm{k}_{2}\right\}\right)$ \\
& \#Context $\backslash$ External $\backslash$ Rivalry $\left(\left\{\mathrm{k}_{3}\right\}\right)$ \\
\hline Combination of & \#Attribute $\backslash$ Idiosyncrasy $\left(\left\{\mathrm{a}_{3}\right\}\right)$ \\
Non-transferable, Shared & \#Attribute $\backslash$ Specificity $\left(\left\{\mathrm{a}_{4}\right\}\right)$ \\
Resources: & \#Attribute $\backslash$ StrategicComplementarity $\left(\left\{\mathrm{a}_{5}\right\}\right)$ \\
\#Event $\backslash$ CombinationOfResources & \#Attribute $\backslash$ Organisational Complementarity $\left(\left\{\mathrm{a}_{6}\right\}\right)$ \\
$(\mathbf{R} \rightarrow\{\mathbf{c}\})$ & \#Attribute $\backslash$ CoordinationMechanism $\left(\left\{\mathrm{a}_{7}\right\}\right)$ \\
& \#Context $\backslash$ Internal $\backslash$ SpecificRelationship $\left(\left\{\mathrm{k}_{4}\right\}\right)$ \\
& \#Context $\backslash$ Internal $\backslash$ IndosyncraticResourceStock $\left(\left\{\mathrm{k}_{5}\right\}\right)$ \\
\hline Interchange of Information and & \#Attribute $\backslash$ CommonKnowledgeBase $\left(\left\{\mathrm{a}_{8}\right\}\right)$ \\
Knowledge: & \#Attribute $\backslash$ ExchangeRoutines $\left(\left\{\mathrm{a}_{9}\right\}\right)$ \\
\#Event $\backslash$ InterchangeOfKnowledge & \#Attribute $\backslash$ ExpertsAvailable $\left(\left\{\mathrm{a}_{10}\right\}\right)$ \\
$(\mathbf{R} \rightarrow\{\mathbf{i}\})$ & \#Attribute $\backslash$ FlowOfProfessionals $\left(\left\{\mathrm{a}_{11}\right\}\right)$ \\
& \#Attribute $\backslash$ FormalIncentives $\left(\left\{\mathrm{a}_{12}\right\}\right)$ \\
& \#Attribute $\backslash$ InformalReciprocity $\left(\left\{\mathrm{a}_{13}\right\}\right)$ \\
& \#Attribute $\backslash$ Sanctions $\left(\left\{\mathrm{a}_{14}\right\}\right)$ \\
& \#Context $\backslash$ Internal $\backslash$ SpecificRelationship $\left(\left\{\mathrm{k}_{4}\right\}\right)$ \\
& \#Context $\backslash$ Internal $\backslash$ IdiosyncraticResourceStock $\left(\left\{\mathrm{k}_{5}\right\}\right)$ \\
\hline
\end{tabular}

After a qualitative survey, the procedure for classification of empirical evidence using a technique of Content Analysis (Krippendorff, 2013) highlights all instances of the types of events in the units of analysis and their theoretical relationships.

In the structured text narrative, the segments of text, known as registration units, have their latent meaning defined by some codes assigned because of the interpretation by the researcher. Coding is the procedure by which empirical data becomes organised into units of meaning. This approach allows a systematic, accurate description of the relevant characteristics of each evidence of a construct in the units of analysis. In the case studies, the unit of analysis is a project of the firm carried out together with some of its partners in the organisational surroundings. All registration units must have at least one code assigned for attributes of the corresponding type of event.

Answering the research question consists of the differentiation of a subset of instances for the event of Generation of Capabilities and Economic Goods $(\mathrm{G})$ that would have a systemic nature 
$\left(\left\{\mathrm{g}^{\prime}\right\}\right)$. Nonetheless, a new event outcome introduces ambiguity into the grammar because there are instances acknowledged using either $\{\mathrm{g}\}$ or $\left\{\mathrm{g}^{\prime}\right\}$ as a terminal symbol. A possible solution is to hypothesize a set of contextual conditions $\left(\left\{\mathrm{k}_{1}, \mathrm{k}_{2}, \mathrm{k}_{3}, \mathrm{k}_{4}, \mathrm{k}_{5}\right\}\right)$ that could explain this surprising fact before testing all possible combinations of them against data.

\subsection{Inductive Configuration Analysis using the Quine-McCluskey Algorithm}

Each type of critical event in a generative process represents a deterministic action or interaction in which contextual conditions allow its occurrence. Usually, deterministic nature does not characterise social phenomena, but a kind of category of decision-making events generated by rational agents represented in a linear rule-based fashion regarded as a deterministic set-theoretic relation is such a realistic assumption.

In decision-making events, agents choose one of the alternative outcomes for a type of event, but they are contingent on the contextual conditions in the empirical settings as causal parameters - evidence of the deterministic nature of that occurrence. Thus, this data analysis procedure consists of determining all configurations of contextual conditions that are causal for the outcome of interest relying on all instances of this type of decision-making event in the same empirical setting.

The research model uses three types of critical events. Two or more event outcomes associated with each type of event generated by such a set of alternative transition rules and their hypothesised contextual conditions come from a theoretically informed "guess" about what enables the occurrence of each event outcome (Table 2).

Table 2. The contextual conditions for the outcomes of interest in each of the analysed events.

\begin{tabular}{|c|c|c|}
\hline Types of Events & Event Outcomes & Index Symbols for Contextual Conditions \\
\hline $\begin{array}{l}\text { Generation of } \\
\text { Capabilities and } \\
\text { Economic Goods for the } \\
\text { Socioeconomic System }\end{array}$ & $\begin{array}{l}\text { [1] systemic } \\
{[0] \text { not systemic }}\end{array}$ & $\begin{array}{l}\mathrm{k}_{1}(\text { in }\{\mathrm{g}\}) \text { impact of the systemic problems } \\
\mathrm{k}_{2}(\text { in }\{\mathrm{g}\}) \text { restricted market opportunities } \\
\left.\mathrm{k}_{3} \text { (in }\{\mathrm{g}\}\right) \text { appropriability of economic rents }\end{array}$ \\
\hline $\begin{array}{l}\text { Combination of } \\
\text { Idiosyncratic, } \\
\text { Non-transferable, } \\
\text { Shared Resources }(\{c\})\end{array}$ & $\begin{array}{l}{[1] \text { idiosyncratic }} \\
{[0] \text { not }} \\
\text { idiosyncratic }\end{array}$ & $\begin{array}{l}\mathrm{k}_{4} \text { (in }\{c\} \text { ) specificity of some firm's } \\
\text { relationships } \\
\mathrm{k}_{5} \text { (in }\{c\} \text { ) idiosyncrasy of the firm's stock of } \\
\text { resources }\end{array}$ \\
\hline $\begin{array}{l}\text { Exchange of Information } \\
\text { and Knowledge }(\{\mathrm{i}\})\end{array}$ & $\begin{array}{l}{[1] \text { idiosyncratic }} \\
{[0] \text { not }} \\
\text { idiosyncratic }\end{array}$ & $\begin{array}{l}\mathrm{k}_{4} \text { (in }\{\mathrm{i}\} \text { ) specificity of some firm's } \\
\text { relationships } \\
\mathrm{k}_{5} \text { (in }\{c\} \text { ) idiosyncrasy of the firm's stock of } \\
\text { resources }\end{array}$ \\
\hline
\end{tabular}

There is a set of algorithms for Qualitative Comparative Analysis (QCA) supporting the configurational studies using empirical evidence of discrete, linear relationships (Ragin, 1987). In this empirical study, the qualitative nature of evidence requires a procedure using configurational analysis based on categorical variables. These event outcomes took part in the development of a social phenomenon having a process-like nature. Hence, the assessment of configurations of 
contextual conditions supporting the occurrence of a set of instances of the outcome of interest applies to the empirical setting under investigation.

After the classification of evidence for a set of instances of the theoretical constructs defined for each type of event, the researcher must organize the bulk of structured empirical evidence in a relational database. The classification of outcomes of a type of event relies on the observed attributes $\left(\left\{\mathrm{a}_{\mathrm{i}}\right\}\right)$ of the corresponding construct.

In brief, conjunctions of contextual conditions empirically observed and calculated by configurational analysis discriminate index symbols. Such symbols make alternative production rules departing from a specific system state with two or more alternative event outcomes to become context-sensitive. For all combinations of the contextual conditions related to each alternative outcome of a type of event, there must be a context-sensitive production rule in the corresponding system state. Each of these conjunctions is sufficient for the event outcome to take place, even though it may not be necessary for any of them. If a contextual condition occurs in all conjunctions, it is necessary for the outcome; or else if it occurs solely, that is, in the absence of all other hypothesised conditions, then it is sufficient. It is all about the Stuart Mill's method of difference (Thiem, 2014).

\subsection{Retroductive Sequence Analysis using the Generative Grammar The- ory}

The concept of Generative Grammar represents such a set of rules for the generation of a category of chains of discrete symbols, also called strings or sentences, which is a formal language. Therefore, a formal grammar $(\mathrm{G})$ explains how an infinite set of sentences of a formal language $(\mathrm{L})$, each of them consisting of symbols from a finite set called alphabet $\left(\sum\right)$, are generated by a finite set of rules $(\mathrm{P})$ that constitutes the grammar itself. Given the grammar $\mathrm{G}=(\mathrm{N}, \Sigma, \mathrm{P}$, S) and its respective generative binary relation $\Rightarrow_{G}$ in $(\Sigma \cup N)^{*}$, a formal language $L(G)$ is the set $\left\{\mathrm{w} \epsilon \Sigma^{*} \mid \mathrm{S} \Rightarrow_{\mathrm{G}^{*} \mathrm{~W}}\right.$ \} of string-like sentences derived from a sequence of activations of some production rules in $\mathrm{P} \epsilon(\Sigma \cup \mathrm{N})^{*}$ starting at the non-terminal symbol S, which is the ordered set of derivations $\left\{\mathrm{W} \epsilon(\Sigma \cup \mathrm{N})^{*} \mid \mathrm{S} \Rightarrow_{\mathrm{G}^{*} \mathrm{~W}}\right.$.

Each production rule $(\mathrm{P})$ represents a relationship between pairs of strings consisting of some elements of the alphabet set $\left(\sum\right)$, called terminal symbols, and of the set of states $(\mathrm{N})$, called nonterminal symbols. Between the grammar rules, at least one must have the non-terminal symbol $\mathrm{S} \in \mathrm{N}$ on the left side.

The paradigm of Generative Linguistics (Chomsky, 1956, 1959) which encouraged the design this systematic, retroductive sequence analysis procedure is still suitable to describe the empirical patterns in process-like phenomena. The proposed qualitative methodology assumes that decision-making events rely upon deterministic rules using combinational logic. It also assumes that complex, dynamic and contingent processes rely on some mechanisms in the form of a set of deterministic rules acknowledging a domain of sequences of event outcomes.

Consider configuration analysis embedded into within-case sequence analysis tests for conjunctions of contextual conditions associated with a surprising event outcome. They comprise a set of instances of this type of event. In addition, the researcher runs configurational analysis for 
each system state with a set of alternative transition rules triggered by contextual conditions in instances of the category of social process under analysis.

Whenever an agent performs a decision-making event, the hypothesis of deterministic causal relation means that a configuration of contextual conditions takes place in the empirical setting before any action. It is the case of all instances of this event resulted from the same deterministic function embedded in the decision-maker. Configuration analysis relying on a technique such as QCA is applicable for the inductive inference of a logic formula. The deterministic relationship of causal nature between decision-making events becomes the critical assumption. Consider generative mechanisms that are inherent to the social structures conditioning the behaviour of the agent in such a concrete situation within a particular range of space and time. In conjunction with some specific configurations of contextual conditions enabling the activation of these mechanisms, if they explain the generation of all instances of that type of event, then such a deterministic relationship exists.

After configuration analysis, each configuration of contextual conditions in a specific system state suggests a new production rule in the generative grammar model for the social process under enquiry. If the mutual exclusion of all possible event outcomes is a valid assumption, then there is no intersection between the sets of configurations of contextual conditions for each one of them. Contrarily, ambiguity is inherent to such a system state, and further exploratory research is still necessary to discover previously unknown contextual conditions. Replacing a set of alternative state transition rules by equivalent context-sensitive rules eliminates ambiguity. In the case of $\mathrm{G} \rightarrow\{\mathrm{g}\}$ and its alternative production rule $\mathrm{G} \rightarrow\left\{\mathrm{g}^{\prime}\right\}$, at least the last one must turn out to be a context-sensitive rule, or $\mathrm{G} \rightarrow \mathrm{K}\left[\mathrm{g}^{\prime}\right],\{\mathrm{g}\}$ in the form of Indexed Grammars (Aho, 1968, 1969). Otherwise, the researcher should endorse a stochastic process model to grasp ambiguity in this set of alternative transition rules.

The configuration analysis of the raw data collected in the empirical setting suggests some modifications to theoretical propositions translated into the initial grammar, which arises in the first sequence analysis. The sequence of events highlighted in the structured text narrative is the only evidence of the generative mechanisms proposed by the grammar model translated from the theory. The rules of the grammar reflect the set of theoretical propositions, adjusted to the design principles of the generative grammars (Figure 1).

The Qualitative Sequence Analysis research approach does not consider the attributes that manifest the occurrence of an event because Qualitative Content Analysis already does it. In the Process Tracing technique, there is no benefit to analyse this kind of classificatory attribute. The terminal symbols standing in production rules of a formal grammar describe the outcomes of events only, not their discriminative attributes. The example of a categorical-generative structure is graphically representable as in Figure 1.

The initial grammar (S) of the competence development process $(\mathrm{CD})$ has a recursive rule $\mathrm{CD} \rightarrow$ GG, CD denoting the pattern that there are two or more contributions of the firm to the search for a solution to a particular competitive problem. This rule pushes CD into the stack representing the working memory of the agent (using the Last In First Out stack of the Pushdown automaton), which are the types of events expected to take place in the future. Nevertheless, this context-free grammar does not acknowledge a context-free language yet, but a regular language. Even though 

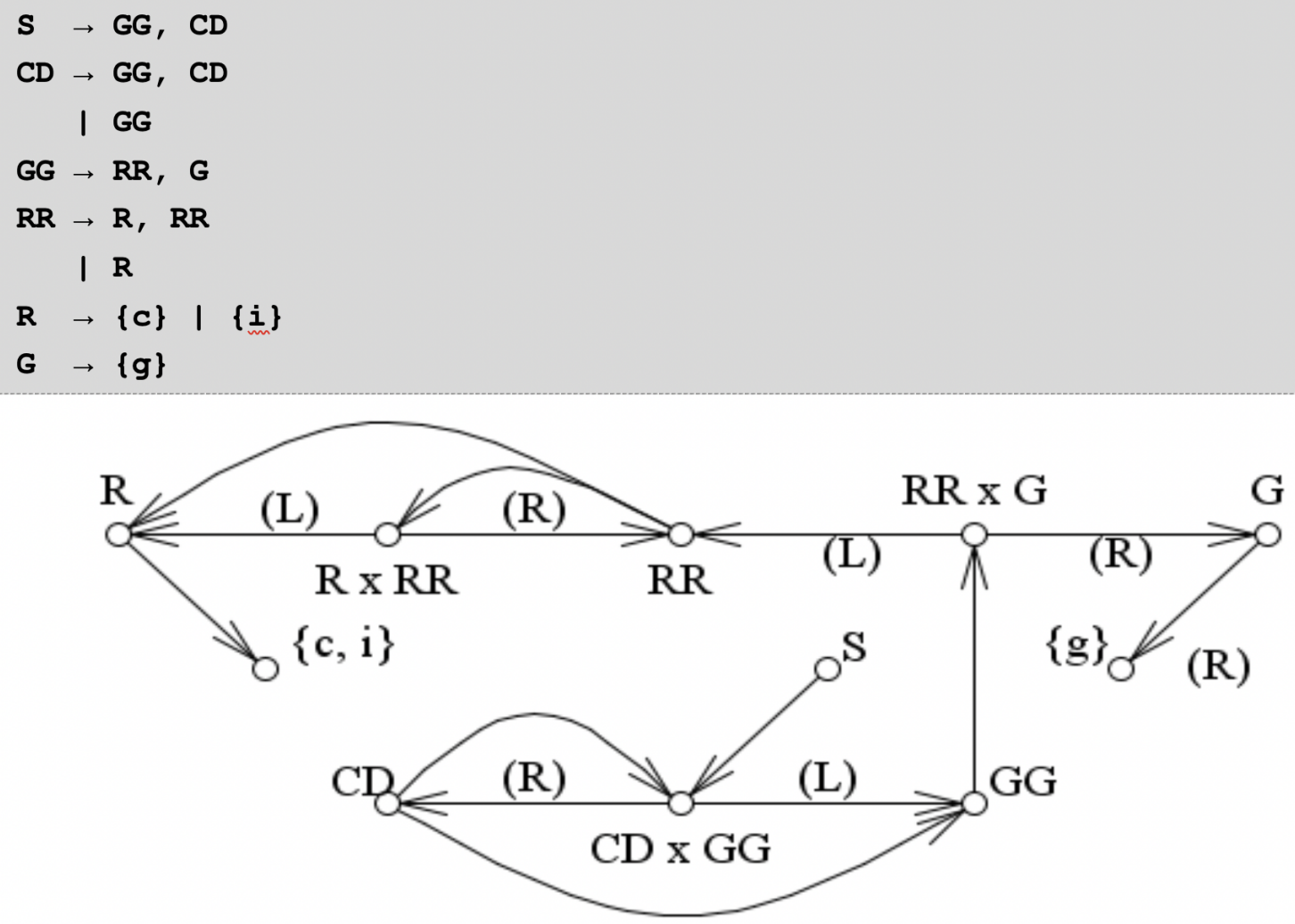

Fig. 1. The initial categorical-generative structure of the competence development process.

the competence-based view of the firm predicts there is such a recursive relation between projects required to generate an economic good, the formal grammar above does not acknowledge it. This would increase the computational complexity of the grammar with a recursive rule pushing intermediary goods on the stack; including at least one systemic good needed to generate an economic good at the end of this instance of the social process. The goal of this research is the acknowledgement of configurations of contextual conditions enabling the generation of a systemic economic good $\left(\left\{g^{\prime}\right\}\right)$. Consequently, competence development (CD) turns out to be a contingent process. Since it is possible to accept this feature as a strictly context-sensitive production rule of such a contingent mechanism, the extended category of social process, without acknowledging any recursive rule, still belongs to the class of regular languages.

Because of the cumulativeness and equifinality features of these processes (Abbott, 1990, 1995), it is not trivial to predict the precise moment of the transition between two states of the generative grammar model based on the known types of events and mechanisms. In contrast, the goal of the process tracing procedure grounded on the logic of retroduction is to improve the predictability of state transitions, eliminating ambiguities and reducing non-determinism in the grammar by replacing the sets of alternative state-transition rules by equivalent context-sensitive rules. The abduction of a new hypothesis about contextual conditions of activated mechanisms raises the level of the computational complexity of the grammar, which is the main goal of this retroductive, within-case sequence analysis procedure (Easton, 2010; George \& Bennett,2004); although it will 
never become an exhaustive search nor it will ever create a definitive model because that system is open.

\section{Results of the Within-case Analysis}

This section presents the results of each within-case analysis, that is, the systemic competence development processes discovered in each credit union as sequences of capabilities and economic goods generated by the firm in the search for solutions to a systemic problem. The types of social processes underlying the competence development in the firm - the combination of specific assets and capabilities and the exchange of information and knowledge with partners in the organisational surroundings - are in this description too.

\subsection{The Community Dimension Case Study: Saromcredi}

São Roque de Minas is a Brazilian municipality located in the Canastra Mountains, in the midwest of the state of Minas Gerais (MG), with $2,108 \mathrm{~km}^{2}$ and a population that has remained steady for at least twenty years at about seven thousand inhabitants. It is the headquarters of Cooperativa de Crédito de Livre Admissão de São Roque de Minas Ltda., also known by the acronym Saromcredi since its foundation in 1991. In the area of the Canastra Mountains, the most relevant economic activity is agriculture, followed by local services, which is concentrated in the three municipalities having the suitable conditions for scale and diversification of such activity - Cássia, Passos, and Piumhi.

Saromcredi's competitive strategy relies on three core products (Prahalad \& Hamel, 1990). First, the infrastructure for accessing the products and services provided by the credit union. Second, sustainable fundraising for the firm's lending operations. The third core product is a set of channels for dedicated credit lines to grab new customers based upon their economic profile. All products have shown value attributes to retain customers relying on at least one of these core products.

However, Saromcredi has no distinctive core competence for banking and financial businesses. The portfolio of products and services and the infrastructure for accessing them, the sources of funding and fundraising capabilities, and the dedicated credit lines do not differ from the other credit unions of Sicoob. Most of these credit unions offer the same service found in any other commercial bank. The local implementation of these shared core products has shown no customized features differentiating Saromcredi from its potential rivals and other credit unions of the Sicoob system.

Between the projects offered to the community environment in which Saromcredi takes part, those contributing to the solution of a systemic problem make evident an ongoing process of systemic competence development in this credit union (Table 3 and Table 4). This competence development is distinctive when the systemic problem harms the firm's performance in such a way that the benefits exceed the costs of the firm taking part in collective efforts to generate a quasi-public economic good. 
Table 3. The core products and systemic competence development processes of Saromcredi.

\begin{tabular}{lccc}
\hline $\begin{array}{l}\text { Core Products (B) versus } \\
\text { Systemic Competence } \\
\text { Development Processes (C) }\end{array}$ & $\begin{array}{c}\text { Bnfrastructure } \\
\text { for accessing } \\
\text { the products } \\
\text { and services }\end{array}$ & $\begin{array}{c}\text { B2. Sustainable } \\
\text { fundraising for } \\
\text { lending } \\
\text { operations }\end{array}$ & $\begin{array}{c}\text { B3. Channels } \\
\text { for dedicated } \\
\text { credit lines to } \\
\text { reach their } \\
\text { target audience }\end{array}$ \\
\hline $\begin{array}{l}\text { C1. To solve structural } \\
\text { weaknesses in the local } \\
\text { economy with funding from the } \\
\text { credit union. }\end{array}$ & 1 project & 9 projects & 11 projects \\
\hline $\begin{array}{l}\text { C2. To mobilize members of the } \\
\text { credit union and other people } \\
\text { and entities in the local } \\
\text { community around educational } \\
\text { initiatives. }\end{array}$ & 2 projects & & \\
\hline
\end{tabular}

Among 35 projects in which Saromcredi has taken part, at least 23 of them have contributed to the solution of a systemic problem in the community environment. These projects are organised in programs, which comprise competence development in the credit union. The first program searches for solutions to structural weaknesses in each of the four local economic sectors (i.e., agriculture, cattle and cheese, local commerce and tourism) with funding from Saromcredi. The second mobilises people in the boroughs of the Canastra Mountains to attend financial education initiatives hosted in some public events promoted with partners in the region.

The programs suggest that there are two systemic competence development processes in Saromcredi. The first one aims the creation of new business opportunities in the local economy by solving structural weaknesses in each of the four main productive sectors, which creates demand for loans that may benefit the credit union. These projects address structural weaknesses or exploit business opportunities that result from the competitive problems solved. The second

Table 4. The descriptive statistics of the projects, members, and resources of Saromcredi.

\begin{tabular}{lcccc}
\hline Types of Events & Projects & \multicolumn{3}{c}{ Members } \\
\hline $\begin{array}{l}\text { C1. To solve structural weaknesses in the local } \\
\text { economy with funding from the credit union. }\end{array}$ & $\mathbf{3 1}$ & $\mathbf{4 1}$ & $\mathbf{8 2}$ & $\mathbf{2 8}$ \\
\hline P2. Problems in the agriculture value chain. & 9 & 9 & 24 & 4 \\
\hline P3. Problems in the cattle and cheese value chain. & 8 & 13 & 23 & 9 \\
\hline P4. Problems in the tourism sector. & 6 & 7 & 15 & 5 \\
\hline $\begin{array}{l}\text { P5. Problems in small business and infrastructure } \\
\text { sectors. }\end{array}$ & 8 & 12 & 20 & 10 \\
\hline $\begin{array}{l}\text { C2. To mobilize members of the credit union } \\
\text { and other people and entities in the local } \\
\text { community around educational initiatives. }\end{array}$ & $\mathbf{4}$ & $\mathbf{6}$ & $\mathbf{8}$ & $\mathbf{2}$ \\
\hline
\end{tabular}


process concerns the mobilisation of people that are or can turn into members of the credit union to expand the customer base for its products and services.

\subsection{The Regulatory Dimension Case Study: Cooperforte}

Cooperativa de Economia e Crédito Mútuo dos Funcionários de Instituições Financeiras Públicas Federais Ltda (Cooperforte) is the only credit union for the employees of all Brazilian federal government banks (i.e., BB, Caixa, BNB, BASA, BNDES) and public servants of the Central Bank of Brazil. It operates through a nationwide, virtual presence supported by a technological infrastructure for call center and internet banking services. There are only five service stations: the headquarters in Brasília (DF), Belo Horizonte (MG), São Paulo (SP), Rio de Janeiro (RJ) and Porto Alegre (RS).

Cooperforte is among the leaders of the credit cooperative market segment in most of the indices of performance. At the time of this empirical research (2014), Cooperforte was the eighth largest credit union in Latin America and the third of Sicoob, the cooperative system in which it takes part.

While Cooperforte's operations rely upon a nationwide virtual presence, most of the other credit unions of Sicoob operate by a local physical presence, including the two leaders of the cooperative system at the time (Credicitrus and Cocred). The Sicoob's leaders have 50 and 25 service stations compared to the five of Cooperforte, whose operational infrastructure (e.g., the operating system, the internet \& phone banking platform, the internal control, and the risk management) is fully separated of Sicoob. At the time of the data collection, Cooperforte had the smallest administrative cost per member, $\mathrm{R} \$ 382.00$ (about 112,000 members), against $\mathrm{R} \$ 1,825.00$ for Credicitrus (about 50,000 members) and $\mathrm{R} \$ 2,237.00$ for Cocred (about 18,700 members). The virtualization of the operations of Cooperforte enabled operational and administrative cost savings per member.

Cooperforte's business model is idiosyncratic when compared with the other two leaders of Sicoob. The banks of the federal government provide most products and services free of charge to employees (e.g., checking account, credit card) or at lower costs compared to other commercial banks in the market (e.g., insurance, pension plans). However, Cooperforte maintains its business model sustainable by delivering a very small portfolio of loan and saving products and no banking products other than checking account and debit card. Cooperforte's products and services, as well as its operational infrastructure, exist fully separated from Sicoob.

Cooperforte's competitive strategy seems to reveal two core products: (a) the internet-banking infrastructure supporting the remote access to all products and services provided by the credit union and (b) an operational and administrative infrastructure apart of Sicoob. All value attributes of Cooperforte's products and services rely on at least one core product. Cooperforte has no distinctive core competence compared to the other credit unions and rivals. It also has less diversification in both the banking infrastructure and the portfolio of products and services when compared to other institutions in the financial industry. This fact suggests the cost leadership competitive strategy is in use by this credit union. These empirical results are in line with this 
Table 5. The core products and systemic competence development processes of Cooperforte.

Core Products (B) versus Systemic Competence Development Processes (C)
B1. Infrastructure for remote access to the products and services of the credit union
B2. Operational and administrative

infrastructure with efficiency and independence

C1. To develop governance, internal control, and risk management mechanisms.

6 projects

C2. To mobilize members of the credit union and other people and entities in the local community around the idea of cooperativism.

hypothesis such that any distinctive competence will necessarily support this kind of competitive strategy.

Cooperforte is such a critical case study because of its competencies for governance, internal control, and risk management. All of them still manage compliance with regulatory requirements and promote the business sustainability based on these capabilities. Other organisations in the Brazilian credit cooperative systems (e.g., confederation, central cooperatives, and cooperative bank) and the state regulator (i.e., Central Bank of Brazil) also foster shared competence in the credit unions contributing to systemic competitiveness. Nevertheless, Cooperforte's evolution still seems to be distinctive. In line with the theoretical propositions of this work, distinctive systemic competence development takes place if and only if the credit union can appropriate part of the benefits generated for the socioeconomic system in the form of private economic rents.

Some projects of the credit union, which contribute in the search of solutions to the systemic problems that exist in the regulatory environment, highlights the systemic competence development process. Between 18 projects identified in Cooperforte, at least eight of them have contributed to the search for solutions to systemic problems (Table 5).

Table 6. The descriptive statistics of the projects, members, and resources of Cooperforte.

\begin{tabular}{lcccc}
\hline $\begin{array}{l}\text { Systemic Competence } \\
\text { Development Processes }\end{array}$ & Projects & Members & Resources & Exchange \\
\hline $\begin{array}{l}\text { C1. To develop governance, } \\
\text { internal control, and risk } \\
\text { management mechanisms. }\end{array}$ & 6 & 3 & 12 & 5 \\
\hline $\begin{array}{l}\text { C2. To mobilize members of } \\
\text { the credit union and other } \\
\text { people and entities in the local } \\
\text { community around the idea of } \\
\text { cooperativism. }\end{array}$ & 2 & 3 & 3 & zero \\
\hline
\end{tabular}


Cooperforte's strategic objectives were the expansion of the number of members of the credit union and the achievement of operational and administrative independence from Sicoob, but guaranteeing economic efficiency. Still, it is a case of distinctive competence development for the regulatory environment compared with the rivals in the local market (Table 6).

\section{Results of Cross-case Analysis}

The cross-case analysis is the ultimate step of a multiple case study. The main goal is the refinement of the theoretical model by suggesting new constructs, attributes and relationships. It encompasses the analysis of all divergences between the theoretical propositions and the empirical patterns found in each pair of subsequent within-case studies (Easton, 2010; George \& Bennett, 2004). Each divergence is resolved by accepting it as a modification of the theoretical model, but only after identifying all configurations of contextual conditions discriminating all the instances in the set of mutually exclusive event outcomes. The present work implements a Process Tracing technique relying upon a formal model deduced from Generative Grammar Theory. Each theoretical concept must translate into a type of sub-process and each theoretical relation into a kind of generative mechanism working on specific types of sub-processes or types of events. All sub-processes embedded in the category of social processes are under investigation.

Consider the surprising fact introduced as an alternative outcome $\left(\left\{g^{\prime}\right\}\right)$ for the type of event of the generation of capabilities and economic goods in the firm $(\mathrm{G})$. The systemic competence development process (CD') is any chain of capabilities and economic goods generated to satisfy a social structure's need in the environmental surroundings. Systemic competence is a kind of distinctive competence preceded by some firm's partnerships that are unavailable to the competitors and other similar organisations (RR'). This type of sub-process occurs after one or more instances of a surprising fact for the combination of idiosyncratic and non-transferable resources $\left(\left\{c^{\prime}\right\}\right)$ and the exchange of information and knowledge $\left(\left\{\mathrm{i}^{\prime}\right\}\right)$. The modified grammar must acknowledge them (Figure 2).

Each surprising fact suggests the modification of the initial grammar that expands the set of event outcomes; nevertheless, the new outcome introduces ambiguity, whose elimination using rules of the indexed grammar class also increases computational complexity to the level of mildly context-sensitive grammars. Thus, the competence development process (CD) expects at least another economic good $(\mathrm{g})$ in the future after the first one takes place, but some systemic goods $\left(g^{\prime}\right)$ may also take place in the meantime.

Based on the feature of recursion, the parser can trace the composition of economic goods to acknowledge any sequence of events of a concrete category of competence development, although at the cost of increasing complexity. Some conditions in the organisational and environmental surroundings of the firm tracked for all instances of the types of events become configurations related to one of the mutually exclusive event outcomes. Therefore, there is at least one rule like $\mathrm{A}[\mathrm{K} ..] \rightarrow \mathrm{K}[.],. \mathrm{B}[.$.$] . This means that the index symbol \mathrm{K}$ pushed upon the index stack for the hypothesised configurations of contextual conditions relates to the event outcome B. Pay attention that the index stack is expected empty (i.e., []) if there is no evidence of systemic 


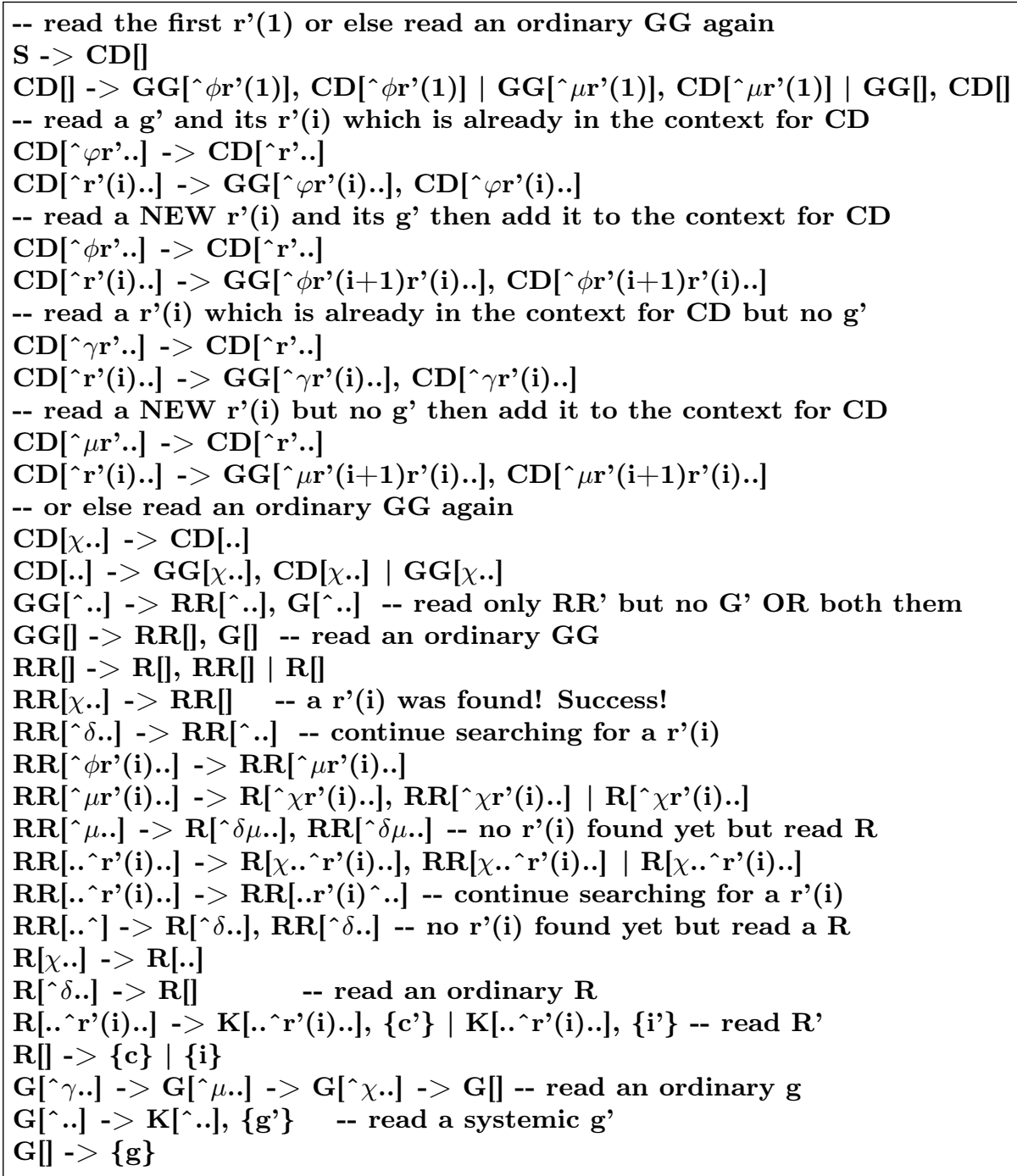

Fig. 2. An extension of the grammar S using the Indexed Grammar formalism (Aho, 1968).

competence development. In this case, the rule $\mathrm{A}[] \rightarrow \mathrm{B}[]$ does not mean the same as $\mathrm{A}[..] \rightarrow$ $\mathrm{B}[.$. , which indicates the index stack is either empty or filled with symbols.

The resulting categorical graph is the same as in Figure 1, except that there are now selfreferenced arrows on $\mathrm{CD}, \mathrm{GG}, \mathrm{G}$ and $\mathrm{R}$ to indicate the function of the test of hypothesis on configurations of contextual conditions in the empirical setting. This graph purposely omits index symbols for hypothesised configurations of contextual conditions $(\mathrm{K})$ as part of the best explanation for the surprising facts; they do not belong to the set of types of events of the category of social process. They represent the internal structure between event outcomes instead of being part of the external structure between sub-processes and events - an issue of using Set Theory rather than Category Theory even though it also implies a natural transformation of the concrete category. 
Consider the hypothesis that any distinctive competence development process is systemic in nature if and only if there are three contextual conditions in the firm's environmental surroundings: (a) high economic impact of the systemic problem; (b) appropriability of part of the benefits generated by the firm for the system in the form of private economic rents; and (c) high rivalry in the local market with no possibility of entering into other markets. Among these three hypothesised conditions to the occurrence of the development of systemic competence, only "Rivalry" (c) was not considered a necessary condition; it could not be verified empirically in all instances of the type of event for the generation of capabilities and economic goods in the benefit of the socioeconomic system in which the firm is positioned. There are two functionally equivalent production rules suggested, but one of them does not acknowledge this contextual condition (Figure $3)$.

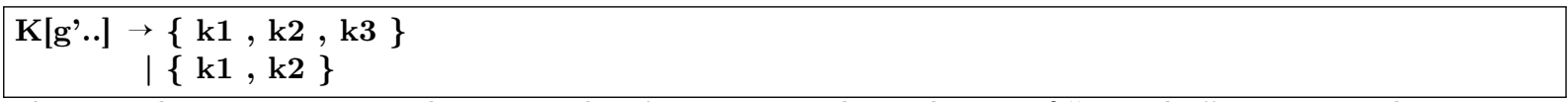

Fig. 3 The environmental surrounding's contextual condition of "Rivalry" is optional.

The event outcomes of the underlying process for the combination of idiosyncratic, non-transferable resources $(\{c\})$ and the exchange of information and knowledge $(\{\mathrm{i}\})$ both take place alternately until the occurrence of a single event of generation of capabilities and economic goods $(\{\mathrm{g}\})$. This is a recurring empirical pattern. Still, it is not possible to predict the occurrence of each event solely based upon the contextual conditions in the environmental and organisational surroundings of the firm because of the cumulativeness feature of a category of social processes; configurations of contextual conditions are necessary but eventually not sufficient for a type of event outcome to occur.

Either \#Context $\backslash$ Internal $\backslash$ SpecificRelationship $\left(\mathrm{k}_{4}\right)$ or \#Context $\backslash$ Internal $\backslash$ ResourceStock $\left(\mathrm{k}_{5}\right)$ is necessary for the occurrence of the corresponding type of event for the combination of idiosyncratic, non-transferable resources (Figure 4).

\section{$\mathrm{K}\left[\mathrm{c}^{\prime} \cdot.\right] \rightarrow\{\mathrm{k} 4, \mathrm{k} 5\} \mid\{\mathrm{k} 5\}$ \\ $\mathrm{K}\left[\mathrm{i}^{\prime} ..\right] \rightarrow\{\mathrm{k} 4\}$}

Fig. 4. The contextual conditions "ResourceStock"and "SpecificRelationship".

In contrast, the condition \#Context $\backslash$ Internal $\backslash$ ResourceStock $\left(\mathrm{k}_{5}\right)$, or the idiosyncrasy of the firm's resource stock, is difficult to occur empirically in the instances of the event outcome for exchange of information and knowledge. Based on the researchers' theoretical and substantive knowledge, it is recommended that the modified grammar model should not have this contextual condition anymore.

The contextual condition $\left\{\mathrm{k}_{4}\right\}$ enables $\left\{\mathrm{c}^{\prime}\right\}$ and $\left\{\mathrm{i}^{\prime}\right\}$ to occur, although $\left\{\mathrm{k}_{5}\right\}$ enables only $\left\{\mathrm{c}^{\prime}\right\}$ to occur. In an attempt to monitor the presence of contextual conditions for events of an interorganisational relationship $(\mathrm{R})$ and generation of capabilities and economic goods $(\mathrm{G})$ in the firm revealed by Configuration Analysis, such an extended formal grammar is proposed using $\mathrm{K}\left[\mathrm{c}^{\prime}\right]$ and $\mathrm{K}\left[\mathrm{i}^{\prime}\right]$. The acknowledgment of this event outcome in the chain of terminal symbols takes place if and only if the verification of exogenous contextual conditions in the surroundings of the firm precedes it.

In conclusion, acknowledging the feature of recursion in the competence development process 
increases the complexity of the formal grammar described, in which context-sensitiveness is not strict anymore. Recall it is only necessary to acknowledge the feature of contingency of the systemic competence development process. The parsing task always turns out to be more difficult if the computational complexity of the formal grammar increases. For example, the grammar does not monitor the minimum number of systemic goods generated because of the additional complexity required to answer the research question. In addition, a grammar acknowledging only the feature of contingency can parse more instances than a grammar acknowledging the features of recursion and contingency. Nevertheless, the goal of this research approach is to test more complex grammar models against data in order to explain the surprising fact. If the empirical data is not enough to be conclusive, then there is a need to collect more data.

Any sequence of projects is planned in advance to generate a kind of economic good, but it admits changes because of unanticipated events to such an extent that the competence development process becomes contingent on some past event outcomes; the historical context of an instance of the concrete category of social process under study. Nevertheless, the precedence between the economic good, which is the goal of the process of competence development, and other intermediary goods that are necessary to build up the first one, eventually including one or more systemic goods, takes place in the configuration of the pushdown automaton. All intermediary goods pushed above the economic good on the bottom of the stack are in the exact order that they take part in the assembling process.

In addition to the hypothesis of recursion in the category of competence development process, one that is not tested neither by the first modified grammar (Figure 5), nor by the second grammar (Figure 6), there is the precedence of at least one event outcome of information and knowledge exchange $\left(\left\{i^{\prime}\right\}\right)$ before zero or more combinations of shared idiosyncratic resources $\left(\left\{c^{\prime}\right\}\right)$. Again, a test of the hypothesis of a generative mechanism improves the realism of the process model, but at the cost of increasing the complexity of the formal grammar. Although the theory suggests this is another unobservable generative mechanism, the observed pattern of events using the empirical evidence from those credit unions is still not conclusive. Consequently, more data or even more case studies are still necessary to keep going on this line of research.

\section{Conclusions}

There are many existing social structures conditioning the firm's strategic behaviour to solve competitive problems that improve the market functioning. The economic theory acknowledges this kind of social phenomenon. In addition, this work proposes that the search for solutions to systemic problems can turn into a competitive strategy of the firm when contextual conditions make this behaviour rational. If a competitive problem is systemic in nature, then some social structure can establish needs that the firm seeks to satisfy in the search for solutions to it. However, it is possible if and only if there is a high economic impact of the problem on the profitability of the firm and it is possible the appropriation of part of the benefits generated for the socioeconomic system in the form of private rents.

There are some organisational capabilities and economic goods generated in the firm enabling problem-solving actions for the benefit of its socioeconomic system. These are actions not orien- 


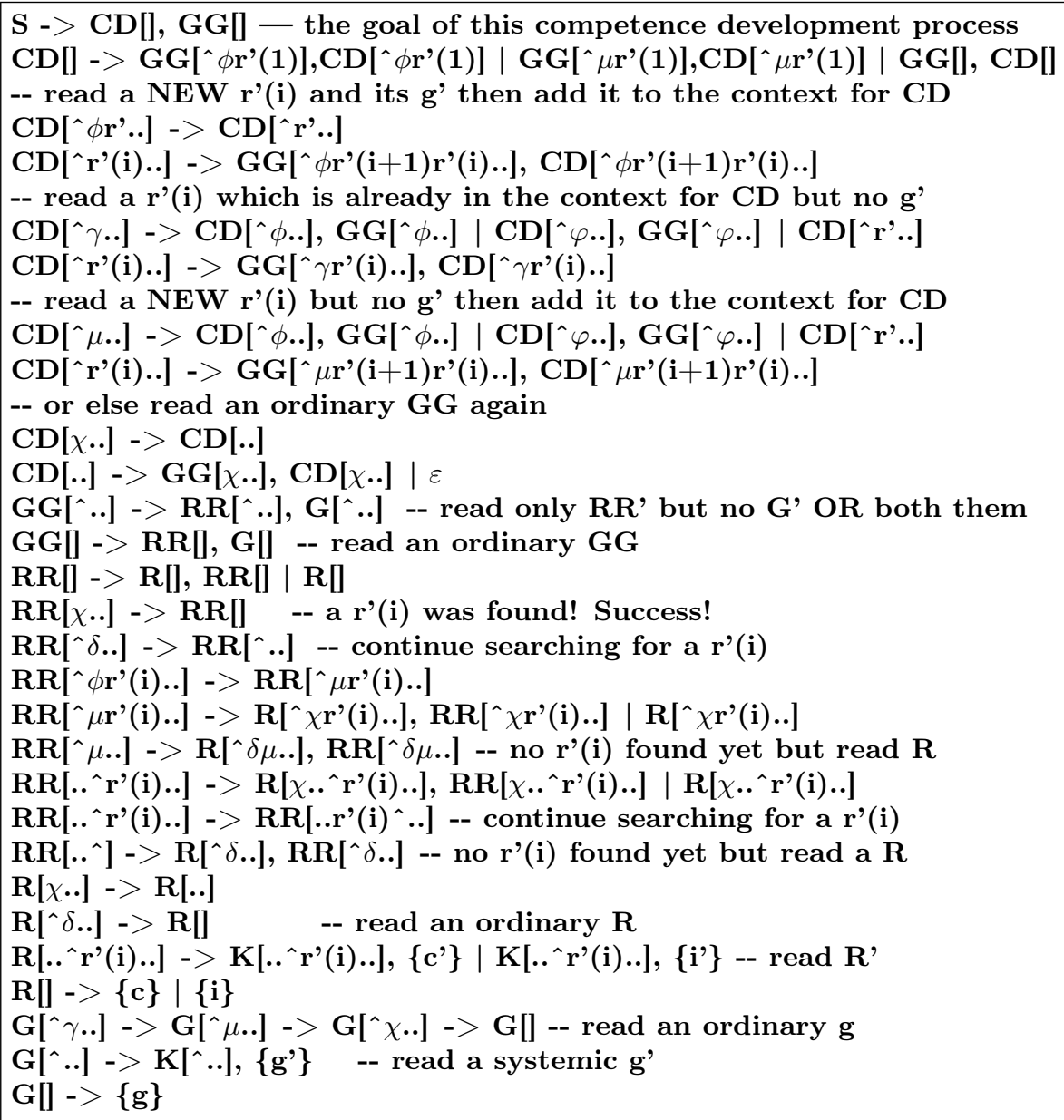

Fig. 5. An extended grammar $\mathrm{S}$ that is mildly context-sensitive with recursion.

ted to market needs, but to another kind of opportunity to create economic rents. Some projects of the firm do not relate to consumers' needs defined in the market but to socioeconomic system's needs defined in other social structures in charge of its governance. The market and all other social structures supplementing it are environmental dimensions creating opportunities and threats to the firm. Most strategic management studies focus on the market dimension, but this research found empirical evidence that other social structures create opportunities to generate private economic rents, which can be as relevant to the growth of the firm as those generated in the market. The problems in the socioeconomic system that are constraints on the performance of the firm are systemic in nature: mechanisms of market price and state intervention cannot solve them.

The present research concludes that the firm's competitive strategy can rely partially upon distinctive competence development to contribute to the search for solutions to systemic problems. Any systemic competence supporting the economic growth of the firm is in line with its competitive strategy. In this situation, economic growth may occur because of the strategic positioning of the firm not only in the market structure but also in a kind of systemic structure surrounding 
it. When the commitment of the firm to systemic problem-solving by collective action means an opportunity to create economic rents, it may be the case of distinctive systemic competence development in the firm helping to create a sustainable competitive advantage.

If social structures of governance only impose constraints on the firm's behaviour that is profitmaximising in perfectly competitive markets, then distinctive contribution of the firm to systemic competitiveness is not economically possible. The generation of capabilities and economic goods to satisfy the needs defined in the social structures in charge of solving the competitive problems in the socioeconomic system would be a source of costs only. According to the rational behaviour assumption, only industry supporting institutions would implement projects to solve systemic problems in the socioeconomic system, but rarely firms. In this case, there would be no distinctive systemic competence development in the firm embedded in a socioeconomic system.

This kind of conceptual distinction between cooperation for competition in the market and cooperation for contribution to social structures of economic governance relies on the mode of exploitation of the resources created collectively. This kind of rationality seeks sustainable competitive advantages in markets by improving the socioeconomic system as well. Further research, particularly on the evolution of ecosystems over time, may improve the proposed analytical framework and methodology, but it may not be the case to apply it to non-local research questions because of the critical realist assumptions and the qualitative, set-theoretic nature of the mathematical model in use.

A research strategy of multiple cases study using the Process Tracing technique aimed to refine theory that relies upon a retroductive procedure of sequence analysis and a formal model deduced from Generative Grammar Theory is the main contribution of this work to qualitative methodology. The process tracing approach to enquiry targets to explain a kind of surprising or anomalous fact that is inconsistent with the widely acknowledged theory. This is the case of the chain of projects performed by the firm to satisfy systemic needs rather than those of consumers in the market.

However, a process tracing research approach tackled in a purely descriptive fashion does not comply with the quality criteria of most of the researches in the mainstream paradigms of economics and management. Our work deduces a discrete mathematical model from Formal Language Theory enabling a systematic, retroductive, sequence analysis procedure implementing the Process Tracing technique, which relies upon the assumptions of Critical Realism. There has never been a mathematical model guiding a data analysis procedure in line with this epistemological paradigm.

Category Theory is a kind of language for description and analysis of mathematical models that are either discrete or continuous in nature. Therefore, it applies for either qualitative or quantitative research since it is a tool to specify natural transformations and to check the functional equivalence between pairs of theoretical relations within a couple of empirical models in use. In this sense, the transformation of the concepts in the starting model of empirical data analysis into functionally equivalent concepts of another model preserves the internal structure of the existing relations between them. This is a valid assumption for instances of a structure-preserving map from empirical patterns in a collected data set into the given theoretical model. This research quality criterion of model equivalence validity is still uncommon in the social sciences literature. 
In this sense, the proposed methodology is a kind of semiosis (Peirce, 1907) in the studying of chains of empirical events using a grammar model and the language of Category Theory too.

Therefore, this work raised the research question about the competitive advantage of the firm getting involved in collective efforts in the search of solutions for systemic problems relying on the assumption of contextual rationality in competitive markets. Unquestionably, there is a need for statistical models enabling quantitative research in this kind of research paradigm based on the assumption of the algorithmic complexity of social phenomena. However, the complex, dynamic and contingent nature of these processes also established another need for a categorytheoretic modelling approach that preserves the functional equivalence between the models in use. This kind of qualitative assessment is often necessary in the same way that qualitative assessment occurs in dynamical systems analysis. The finite automata realising regular grammars are discrete-state and discrete-time dynamical systems. Thus, a quantitative, statistical model of either regular grammar or context-free grammar, which are respectively Hidden Markov Chain and Stochastic Context-Free Grammar, is an adequate research modelling approach after qualitative assessment of the kind discussed here.

Acknowledgements. To my former math teacher Maria José Zamith.

\section{References}

Abbott, A. (1990). A primer on sequence methods. Organization Science, 1(4), 375-392.

Abbott, A. (1995). Sequence Analysis: New Methods for Old Ideas. Annual Review of Sociology, 21, 93-113.

Aho, A. V. (1968). Indexed Grammars---An Extension of Context-Free Grammars. Journal of the ACM, 15(4), 647-671. https://doi.org/10.1145/321479.321488

Aho, A. V. (1969). Nested Stack Automata. Journal of the ACM, 16(3), 383-406.

https://doi.org/10.1145/321526.321529

Barker, C. (2005). Cultural Studies: Theory and Practice. London: Sage Publications.

Bhaskar, R. A. (1975). A Realist Theory of Science. London: Verso.

Blake, A. (1937). Canonical Expressions in Boolean Algebra. University of Chicago.

Borgatti, S. P., \& Foster, P. C. (2003). The Network Paradigm in Organizational Research: A Review and Typology. Journal of Management, 29(6), 991-1013. https://doi.org/10.1016/S01492063_03_00087-4

Borrás, S., \& Edquist, C. (2013). Competence Building[202F?]: A Systemic Approach to Innovation Policy (No. 28). Lund, Sweden.

Bourdieu, P. F. (1977). Outline of a Theory of Action. Cambridge, MA: Cambridge University Press.

Bourdieu, P. F. (1980). The Logic of Practice. Cambridge, MA: Polity Press. 
Bourgeois III, L. J. (1984). Strategic Management and Determinism. Academy of Management Review, 9(4), 586-596.

Braga, B. da R. (2016). Crafting theory for a complex, dynamic social phenomenon: a Critical Realist, Grammar-based Process Model. 1st International Symposium on Qualitative Research, (5), 77-82. https://doi.org/10.13140/RG.2.1.4850.4565

Braga, B. da R. (2017). A Categorical-Generative Theory of Social Processes: About Describing a Complex, Dynamic and Contingent Pattern of Decision-Making Events. SSRN Electronic Journal. https://doi.org/10.2139/ssrn.3033880

Braga, B. da R. (2018). A Categorical-Generative Theory of Social Processes: Towards the Ontological and Mathematical Foundations of a Grammar-Based Model for Qualitative Research. In C. A., R. L., S. F., \& M. A. (Eds.), Computer Supported Qualitative Research. ISQR 2017. Advances in Intelligent Systems and Computing (pp. 400-411). https://doi.org/10.1007/978-3319-61121-1_34

Camisón, C. (2004). Shared, competitive, and comparative advantages: a competence-based view of industrial-district competitiveness. Environment and Planning A, 36(12), 2227-2256. https://doi.org/10.1068/a3759

Caves, R. E., \& Porter, M. E. (1977). From Entry Barriers to Mobility Barriers: Conjectural Decisions and Contrived Deterrence to New Competition. Quarterly Journal of Economics, 91(2), 241-262.

Chamberlin, E. H. (1933). The Theory of Monopolistic Competition. Cambridge: Harvard University Press.

Chaminade, C., Lundvall, B.-A., Vang, J., \& Joseph, K. J. (2009). Designing innovation policies for development: towards a systemic experimentation-based approach. In Handbook of Innovation Systems and Developing Countries: Building Domestic Capabilities in a Global Setting. Northampton, MA: Edward Elgar Publishing Limited.

Chandler, A. D. (1962). Strategy and Structure. In Chapters in the history of the industrial enterprise (Vol. 4). Cambridge: MIT Press.

Chandler, A. D. (1992). Organizational capabilities and the economic history of the industrial enterprise. Journal of Economic Perspectives, 6, 79-100.

Chandrasekhar, C. P. (2007). Financial Policies. New York.

Chomsky, N. (1956). Three models for the description of language. IEEE Transactions on Information Theory, 2(3), 113-124. https://doi.org/10.1109/TIT.1956.1056813

Chomsky, N. (1959). On Certain Formal Properties of Grammars. Information and Control, 2(2), 137-167. https://doi.org/10.1016/S0019-9958(59)90362-6

Coase, R. H. (1937). The Nature of the Firm. Economica, 4 (16), 386-405.

https://doi.org/10.2307/2626876

Coleman, J. S. (1986). Social structure and the emergence of norms among rational actors. Paradoxical Effects of Social Behavior, 55-83. 
Crawford, S. E. S. S. ., \& Ostrom, E. (1995). A Grammar of Institutions. The American Political Science Review, 89(3), 582-600. Retrieved from http://www.jstor.org/stable/2082975

DeCarolis, D. M., \& Deeds, D. L. (1999). The impact of stocks and flows of organizational knowledge on firm performance: an empirical investigation of the biotechnology industry. Strategic Management Journal, (20), 953-968.

Doz, Y. (1996). The evolution of cooperation in strategic alliances: Initial conditions or learning processes. Strategic Management Journal, 17, 55-83.

Dyer, J. H., \& Singh, H. (1998). The relational view: cooperative strategy and sources of interorganizational competitive advantage. Academy of Management Review, 23(4), 660-679.

Easton, G. (2010). Critical realism in case study research. Industrial Marketing Management, 39(1), 118-128. https://doi.org/10.1016/j.indmarman.2008.06.004

Eilenberg, S., \& MacLane, S. (1945). General theory of natural equivalences. Trans. Am. Math. Soc., 58(2), 231-[200B?]294.

Esser, K., Hillebrand, W., Messner, D., \& Meyer-Stamer, J. (1995). Systemic Competitiveness New Governance Patterns for Industrial Development. Berlin: German Development Institute.

Esser, K., Hillebrand, W., Messner, D., \& Meyer-Stamer, J. (1996). Competitividad sistémica: Nuevo desafío a las empresas y a la política. Revista de La CEPAL, (59), 39-52.

Finger, M., \& Varone, F. (2006a). Bringing technical systems back in: towards a new European model of regulating the network industries. Competition and Regulation in Network Industries, 1(1), 87-106.

Finger, M., \& Varone, F. (2006b). Governance of network industries: towards European regulators, differentiated regulations, or self-regulation[202F?]? Conference of the Standing Group on Regulatory Governance, 1-17. Bath: European Consortium for Political Research.

Foss, N. J. (1996). Introduction: the emerging competence perspective. In N. J. Foss \& C. Knudsen (Eds.), Towards a Competence Theory of the Firm (pp. 1-12). London: Routledge.

George, A. L., \& Bennett, A. (2004). Case Studies and Theory Development in the Social Sciences. Cambridge: MIT Press.

Goerzen, A. (2007). Alliance Networks and Firm Performance: the impact of repeated partnerships. Strategic Management Journal, 28(October 2004), 487-509. https://doi.org/10.1002/smj

Grant, R. M. (1996). Prospering in dynamically-competitive environments: Organizational capability as knowledge integration. Organization Science, 7, 375-387.

Hertog, J. Den. (1999). General Theories of Regulation. Utrecht, Netherlands: Utrecht University.

Javidan, M. (1998). Core competence: What does it mean in practice? Long Range Planning, 31(1), 60-71. https://doi.org/10.1016/S0024-6301(97)00091-5

Jessop, B. (2001). Complexity , Critical Realism, and the Strategic-Relational Approach: Some Comments on the Critique of Political Economy in the Age of Globalization. International 
Association for Critical Realism Annual Conference, (August), 1-30. Lancaster, UK: Lancaster University.

Kawai, M., Mayes, D. G., \& Morgans, P. J. (2012). Implications of the Global Financial Crisis for Financial Reform and Regulation in Asia (M. Kawai, D. G. Mayes, \& P. J. Morgan, Eds.). Cheltenham, UK: Edward Elgar Publishing Limited.

Krippendorff, K. (2013). Content Analysis: An Introduction to its Methodology (3rd ed.). Thousand Oaks, CA: Sage Publications.

Lawson, C. (1999). Towards a Competence Theory of the Region. Cambridge Journal of Economics, 23(2), 151-166.

Lawson, C. (2004). Competence theories. In S. Fleetwood \& S. Ackroyd (Eds.), Critical Realist Applications in Organisation and Management Studies (pp. 234-252). London: Routledge.

MacLane, S. (1948). Groups, Categories and Duality. Proceedings of the National Academy of Sciences, 34(6), 263-267. https://doi.org/10.1073/pnas.34.6.263

Makadok, R. (2001). Toward a Synthesis of the Resource-based and Dynamic-Capability Views of Rent Creation. Strategic Management Journal, 22, 387-401.

Makadok, R. (2006). The four theories of profit under competition and their interactions: an abbreviated summary. Academy of Management Best Conference Paper, 1-7.

Meyer-Stamer, J. (1998). Path Dependence in Regional Development[202F?]: Persistence and Change in Three Industrial Clusters in Santa Catarina, Brazil. World Development, 26(8), $1495-1511$.

Meyer-Stamer, J. (2005). Systemic Competitiveness Revisited: Conclusions for Technical Assistance. In Mesopartner Working Papers. Duisburg: Mesopartner.

Nelson, R. R., \& Winter, S. G. (1982). An evolutionary theory of economic change. Cambridge: Belknap Press.

OECD. (1992). Industrial Policy Review. Paris.

OECD. (1994). Industrial Structure Statistics. Paris.

Peirce, C. S. (1907). Pragmatism. In The Essential Peirce: Vol. 2 (1998) (pp. 398-433). Bloomington: Indiana University Press.

Pentland, B. T. (1995). Grammatical Models of Organizational Processes. Organization Science, 6(5), 541-556. https://doi.org/10.1287/orsc.6.5.541

Peteraf, M. A. (1993). The cornerstones of competitive advantage: A resource-based view. Strategic Management Journal, 14(3), 179-191. https://doi.org/10.1002/smj.4250140303

Porter, M. E. (1979). The Structure within Industries and Companies Performance. The Review of Economics and Statistics, 61(2), 214.

Porter, M. E. (1990). Competitive Advantage of Nations. Havard Business Review, 1 (Mar./Apr.), 74-91. https://doi.org/10.1002/cir.3880010112 
Post, E. L. (1936). Finite Combinatory Processes-Formulation 1. Journal of Symbolic Logic, 1(3), 103-105. https://doi.org/doi:10.2307/2269031

Prahalad, C. K., \& Hamel, G. (1990). The core competence of the corporation. Harvard Business Review, 68(3), 79-91.

Quine, W. V. (1952). The Problem of Simplifying Truth Functions. The American Mathematical Monthly, 59(8), 521-531. https://doi.org/10.2307/2308219

Ragin, C. C. (1987). The Comparative Method: Moving Beyond Qualitative and Quantitative Strategies. Berkeley: University of California Press.

Robinson, J. (1933). The Economics of Imperfect Competition. London: Macmillian.

Rumelt, R. P. (1984). Towards a Strategic Theory of the Firm. In R. Lamb (Ed.), Competitive Strategic Management (pp. 556-570). Englewood Cliffs: Prentice Hall.

Teece, D. J. (1986). Profiting from technological innovation: Implications for integration, collaboration, licensing and public policy. Research Policy, 15 (6), 285-305.

Teece, D. J., Pisano, G., \& Shuen, A. (1997). Dynamic capabilities and strategic management. Strategic Management Journal, 18(7), 509-533. https://doi.org/10.1002/(SICI)10970266(199708)18:7<509::AID-SMJ882>3.0.CO;2-Z

Thiem, A. (2014). Mill's Methods, Induction, and Case Sensitivity in Qualitative Comparative Analysis: A Comment on Hug (2013). Qualitative \&3 Multi-Method Research, 12(2), 19-24.

Turing, A. M. (1939). Systems of Logic Based on Ordinals. Proceedings of the London Mathematical Society, s2(45), 161-228. https://doi.org/10.1112/plms/s2-45.1.16

Walker Jr., O. C., \& Ruekert, R. W. (1987). Marketing's Role in the Implementation of Business Strategies: A Critical Review and Conceptual Framework. Journal of Marketing, 51 (July), $15-33$.

Wernerfelt, B. (1984). A resource-based view of the firm. Strategic Management Journal, 5(2), $171-180$. 


\section{Biographies}

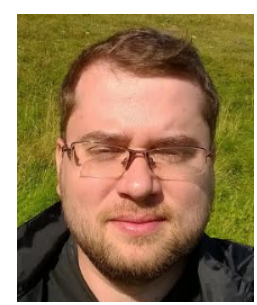

Bruno da R. Braga. Doctor of Science (D.Sc.) in Administration from the University of Brasilia (UnB), Professor of Information Systems at the Federal Institute of Education, Science and Technology of Brasilia (IFB) and Analyst at the Central Bank of Brazil (BCB).

CRediT Statement: 